\title{
Can Structural Timber Foster Short Procurement Chains within Mediterranean Forests? A Research Case in Sardinia
}

\author{
Massimo Fragiacomo ${ }^{1 \Xi}$, Riccardo Riu ${ }^{2}$, Roberto Scotti ${ }^{3}$
}

1 University of Sassari, Department of Architecture, Design and Urban Planning, Palazzo del Pou Salit, Piazza Duomo 6, I-07041 Alghero, Italy

${ }^{2}$ University of Cagliari, Department of Civil and Environmental Engineering and Architecture, Via Marengo n.2, I-09123 Cagliari, Italy

3 University of Sassari, Department of Agriculture, Nuoro Forestry School, Via C. Colombo 1, I-08100 Nuoro, Italy

Corresponding author: e-mail: fragiacomo@uniss.it

Citation:

FRAGIACOMO M, RIU R, SCOTTI R 2015 Can Structural Timber Foster Short Procurement Chains within Mediterranean Forests? A Research Case in Sardinia. South-east Eur for 6 (1): 107-117. DOI: http://dx.doi.org/10.15177/seefor.15-09

Received: 12 Feb 2015;

Accepted: 31 Mar 2015;

Published online: 29 Apr 2015

\section{Abstract}

Background and Purpose: The aim of this paper is to present the idea of a timber short procurement chain as a means to provide an increased value to Mediterranean forests. It is based on the evidence that timber buildings are increasingly used for a number of reasons including sustainability, the speed of erection, and excellent structural and seismic performance. However, most of the timber currently used around the Mediterranean is imported from outside this area.

Materials and Methods: The idea is to use the best part of the tree to produce timber boards, while all the remaining part of the tree including the production waste is used for energy production. Important issues to address are the generally low mechanical properties of locally-grown timber such as maritime pine in Sardinia, which would make some wood-based products such as glue-laminated timber not technically viable. Cross-laminated timber panels are a possible solution to this problem because this wood-based product is manufactured in such a way that even with low-quality timber boards it is possible to obtain a medium quality panel. The panel is made of layers of timber boards with the adjacent layers glued under pressure at a right angle. Another issue is the need to grade the local timber, for which a number of specimens must be tested to destruction in order to identify a visual or a machine-stress grading procedure. Last but not least, the panels must be tested to destruction to correlate their mechanical properties to the properties of the boards.

Results: The preliminary mechanical tests carried out on Sardinia maritime pine confirm that the material is low-grade because it is characterized by large knots and a significant grain deviation. Nevertheless, when used in the cross-laminated panels, the properties are significantly improved due to the layout of the panel which reduces the influence of defects in the boards on the mechanical properties of the panel. 
Conclusions: A timber short procurement chain is a possible means to create job opportunities and reduce depopulation, which is particularly important in several regions of the Mediterranean. By adding value to the forests by means of timber production used in prefabricated components employed in low-rise timber buildings, it is also possible to improve forest management and even extend forested areas which have all positive effects on the environment, the landscape and the reduction of hydrogeological hazard.

Keywords: biomass for energy production, cross-laminated panels, forestry, short procurement chain, sustainability, timber, wood

\section{INTRODUCTION}

In Sardinia, a typical Mediterranean island, the National Forest Inventory (INSC) [1] states that approximately one fourth of the land is covered by woods, considering as such the areas larger than 0.5 ha with tree density above $10 \%$ and potential height above $5 \mathrm{~m}$. The main species are oaks, followed by other broadleaves. Nonetheless, conifers play a relevant role in the island's history and landscape. The average growth of the trees is limited, being estimated in the range of $2(+/-5 \%)$ cubic meters per hectare per year, which is half of the average value in whole Italy. The potential for firewood production is relatively large and traditionally exploited, whereas viable timber production is possible only on very limited land tracts. As a consequence, this production is not really considered relevant in the local silvicultural tradition and all timber used in Sardinia is currently imported (from Austria, Germany, Russia, etc.).

The use of wood as energy source is increasingly important but it is certainly not the best way to exploit the material since it is a low added value product and it terminates the carbon stocking process. Hence the question in the title: could the activation of structural timber short procurement chains, though quantitatively limited, help improve forestry economy in Sardinia and what is its contribution to sustainability? The paper addresses a broad range of different issues that have to be considered and solved in order to make such a development process possible. The activation of a timber short procurement chain is a relevant topic for the whole Mediterranean region (e.g. Greece, Andalusia, Corsica, etc.) as a means to bring some economical development through forestry good practice and wood processing industry.

To address the topic, a joint research partnership involving foresters, wood scientists and engineers has been initiated some years ago in Sardinia. Currently the work is being developed within the "EDENSO" research project ("Sustainable use of Sardinia forests in construction and energy production"). The aim of this project is to ensure the possibility of using locally-sourced timber to construct the structural skeleton of residential buildings. One of the target of the research is in fact the construction of a small buildings using locally grown timber.

The first question to answer was which tree species should be considered for timber production. Conifers, for many reasons, are the most used species, whereas there is no large scale exploitation of broadleaves in the production of wood-based timber products such as glued and cross-laminated timber panels. Some trials have been conducted using eucalyptus in mixed species panels but none with really autochthonous Sardinian species. In this research project, a widely spread and relatively fast growing conifer, maritime pine (Pinus pinaster Ait.), was chosen as the first focus species.

The paper describes the long and complex procedure that has to be successfully completed before making it possible to use a new tree species in the production of structural timber.

\section{SILVICULTURAL ISSUES IN SARDINIA FORESTRY}

The island has witnessed a century long season of pines plantation forestry [2]. The interventions concerned areas of very diverse extensions and were differently motivated 
over the course of time. Large works started in the 1950s and included sand dunes fixation interventions. The need to address the hydrogeological hazard issues motivated the interventions at higher altitudes, covering very large areas. On the other hand, the reforestation served also as a way to provide an income for people living in rural areas where agriculture had suddenly become marginal. Furthermore, the attempt to activate a forestry based productive chain has been cyclically encouraged [3, 4]. Within this 'productive reforestation' strategy, the opportunity to feed the Arbatax paper mill encouraged private owners and public managers to plant large extensions with radiata pine.

According to the National Forest Inventory (INFC), the area covered by conifers in Sardinia was about 50000 ha [1]. The current extension of conifers is almost entirely a result of artificial introduction, initially achieved by seeding and later, since late 1970s, by plantation. Seeds and plants were imported in great quantity and it is quite difficult to trace back the geographic origin of the genetic resources used in most stands. The species used, in order of decreasing surface, are: stone pine (Pinus pinea L.), Aleppo pine ( $P$. halepensis Mill.), Corsican pine (P. nigra Arn.), maritime pine ( $P$. pinaster Ait.), radiata pine ( $P$. pinaster $D$. Don) and other species, also including Cedrus spp. The precise assessment of the relative importance of the species is not straightforward, given the variety of mixed stands that currently exist. Moreover, different species reflect different historical motivations and concern different social and environmental conditions.

The presence of conifers, namely stone, maritime and Aleppo pines, as a part of the autochthonous flora of the island is not easily documented since its heritage is confined to very limited spots. During the artificial expansion phase, almost nothing was done to exploit this genetic reserve and to preserve the pre-existing populations. Beyond the detailed species distinction, from the silvicultural point of view, conifers in Sardinia are divided into two broader groups, the Mediterranean pines (stone, maritime, Aleppo and Corsican pines) and the others, considered exotic species.

Most of these artificial stands share a common problem: they did not receive the care they would have required while developing from young to mature stands. The public financial support considered only the work needed to have the small trees surviving initial competition, which is very labour-intensive. No forest management plan was drawn and very little of the required thinning and pruning was carried out, mainly because it is generally true that the financial value of the wood collected during thinning does not pay for operation costs. Negative consequences of the neglected care are now evident in various different situations: the ecological development is slowed down, excessive amounts of deadwood foster pathogens and fires, stems are underdeveloped and badly shaped, and the stands are fragile.

In 2007 the Sardinia Region adopted the 'Regional forests and environmental plan' (PFAR [5]) with provisions to activate, over the whole island, district by district, participatory largescale planning initiatives. A further focus is on the land properties where, with an appropriate management plan, forests can positively contribute to the possibility of living in the countryside. Main forest management problems of Sardinia are very well tackled, at regional level, in the PFAR initial document.

By connecting PFAR work with INFC results, Campus et al. [6] extended the analysis, framing the island's silvicultural issues in broad macro-categories. For the macro-category 'Forests originated as conifers plantations', the work points out that these stands have to face a quite diversified range of management objectives. Tourism-needs and tourist-related use limitations are the main issues in many coastal/suburban areas. Relatively young stands could still profit of late thinning. Older stands are faced with contrasting options, particularly if local productivity levels are above average. With limited productivity, it is generally a question of how to favour the development of a more autochthonous stand, possibly using the conifer component that is removed as biomass for energy production and deciding whether 
some memory of the plantation should survive or not. If productivity is not severely limited, the regeneration of the pine stand (generally by plantation, though natural regeneration may be a local option) can be taken into consideration. The hypothesis of sustained timber production is proposed with reference to site conditions of this type for maritime pine. This species is in fact quite widespread also in several Mediterranean regions, and has the advantage of being relatively fast growing.

\section{ADVANTAGES OF TIMBER AS A CONSTRUCTION MATERIAL}

Since the construction sector is currently based on environmentally costly processes, there is a great potential for sustainability recovery by reducing the environmental impact of building materials [7]. In addition, the sector is important for achieving the objectives defined in the Kyoto Protocol since the energy required for the management of the built environment is now the main part of the energy costs of the European countries [8]. The ecological balance of a material describes its life-cycle: from extraction of the raw material, through production and processing, until use and disposal. Wood is the only material that requires just water, air and sun to grow. In addition, wood has the ability to incorporate $\mathrm{CO}_{2}$, i.e. wood absorbs the harmful $\mathrm{CO}_{2}$ from the air and returns it to the environment only after combustion. As shown by the European Union in the Sixth Environmental
Action Programme, each cubic meter of wood used in construction corresponds to almost 1 tonne of $\mathrm{CO}_{2}$ that is stored during the entire life of the building, which in this way plays an important role in mitigating climate change.

The total energy consumption for the production of structural timber compared to other building materials such as brick or concrete blocks is $75 \%$ less [7]. This difference derives from the fact that bricks and concrete block production require very high temperatures for a long period of time, which is usually generated by fossil fuels. By contrast, timber production generally implies relatively little emissions and its processing does not require any demanding or expensive technical processes. The disposal of rubble minerals is very expensive while timber waste can be processed and used in woodbased panels or simply burned to produce energy [9]. Last but not least, wood is one of the few renewable building materials which can be produced within a life cycle of 30 to 60 years.

Timber has also the advantage of being aesthetically pleasing, and therefore it is often chosen by the architects both for finishing and for structural members such as columns, beams and ceilings of floors to create a warm and pleasant living environment (Figure 1). In terms of mechanical properties, it is characterized by an excellent strength-to-unit weight ratio, which is approximately the same as steel and almost five times larger than concrete. These results in lightweight structures, like steel structures, that are approximately five times lighter than reinforced concrete structures. The

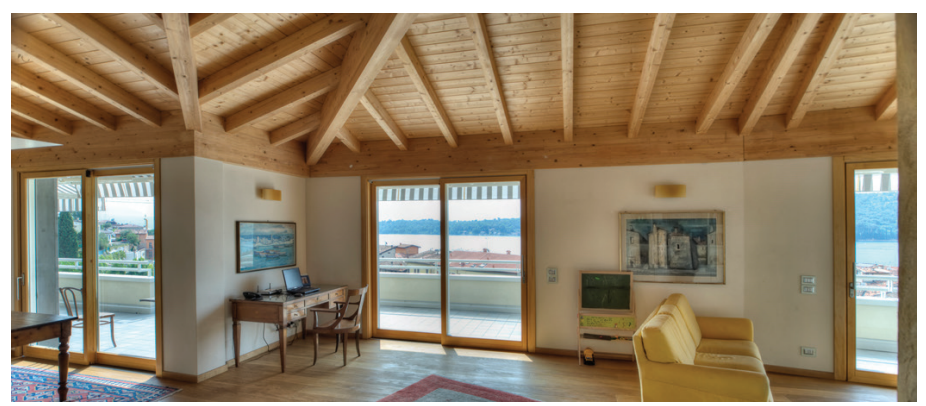

FIGURE 1. Interior of a house where timber has been used for the structural skeleton (walls and roof), for the flooring and for the doors (courtesy of Rubner Holzbau Spa - Bressanone (BZ)). 
advantages of a lightweight structure include reduced seismic actions (which are roughly proportional to the mass of the structure) and hence excellent earthquake resistance, reduced cost of foundations, and the ease of transport and erection.

The reduced weight makes it possible to prefabricate large timber components offsite which can then be easily transported to the building site, craned to a position, and then connected to the other members using simple connections (Figure 2). The connections are usually made of steelwork and metal fasteners such as nails, screws and bolts. The prefabrication and the ease of connection results in a significantly reduced erection time as compared for example to reinforced concrete construction where the concrete is usually cast in situ and therefore a formwork is needed for 28 days to support the fresh concrete in order for it to cure and harden. For these reasons, in a number of cases the investors have decided to build with timber as structural material instead of concrete in order to reduce the construction time [10].

Due to all the advantages listed above, timber is nowadays more and more used not only in central Europe and Scandinavia, but also in several countries of the Mediterranean basin such as Italy, France, Spain, Portugal and Greece where there was no strong tradition in the use of wood in construction. However, in most of these countries timber is not grown locally, but it is imported, often from countries which are very far (Austria, Germany, Russia). The aim of the research project undertaken in Sardinia is to demonstrate the feasibility of using locally grown timber to manufacture modern prefabricated structural components.

\section{ISSUES TO ADDRESS WHEN USING LOCALLY GROWN TIMBER FROM THE MEDITERRANEAN REGIONS}

An important issue to address when using locally grown timber in the Mediterranean regions is the generally low quality of the wood. In Sardinia, for example, most of the plantations have not been subjected to any forest management plan or silvicultural care, resulting in low quality timber, namely timber characterized by large knots, grain deviations, and consequently low mechanical properties (strength and the modulus of elasticity). It is necessary to identify a wood-based product that (i) is of medium quality starting from a low quality timber, and that (ii) can be easily produced in low-cost fabrication plants. Glue-laminated timber is an example of wood-based material that complies with criterion (ii) but not with criterion (i); conversely, Laminated Veneer Lumber (LVL) is an example of a wood-based product complying with criterion (i) but not with criterion (ii).

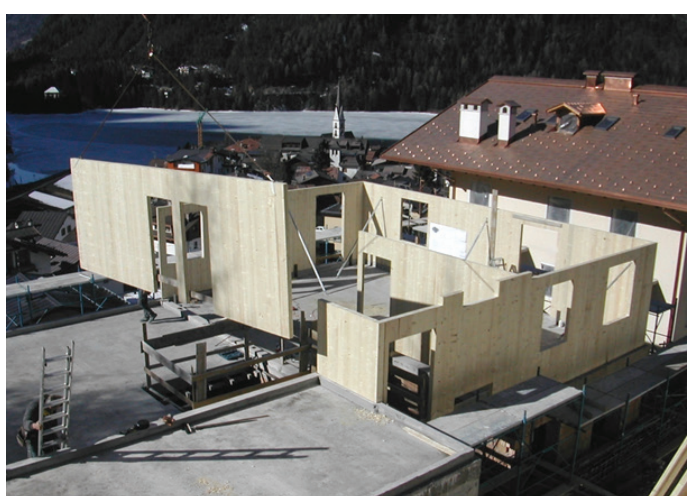

a)

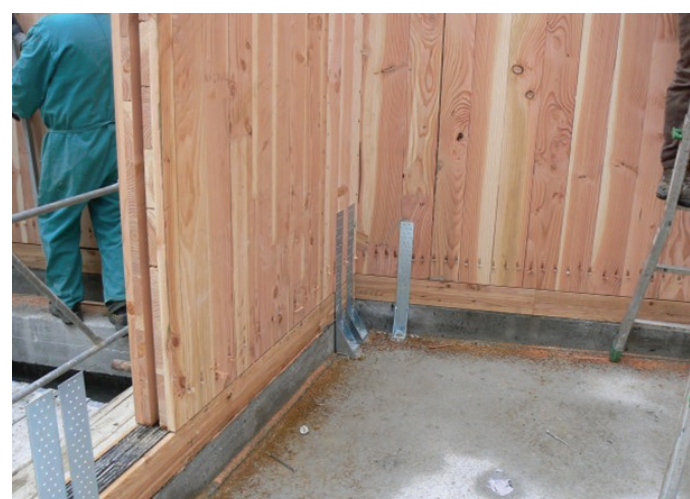

b)

FIGURE 2. (a) Crosslaminated timber wall prefabricated off-site (courtesy of Prof. Ario Ceccotti) and, (b) Metal connectors used to connect the prefabricated panel on-site (courtesy of dedaLEGNO). 
Cross-laminated timber (CLT) was identified as a wood-based product complying with both criteria. CLT is formed in a similar fashion to the more familiar glue-laminated timber beams (glulam), using small sections of timber boards finger jointed and glued together. Unlike glulam, CLT is a bidimensional (plate-like) member, and the adjacent layers of boards are arranged at a right angle (Figure 3). In this way, the effects of a board defect, such as a knot, on the strength of the panel are markedly reduced and therefore a significant improvement in strength with respect to the boards can be attained [11]. CLT has also comparable mechanical properties in its plane, unlike glulam which has excellent mechanical properties in direction of the boards, and poor mechanical properties in the other directions. Last but not least, CLT does not suffer from significant dimensional variations (shrinkage/ swelling) in its plane.

CLT is produced with a hidraulic or pneumatic press which applies the right pressure across the cross layer of boards to ensure an effective gluing process. The presses can have different sizes (and costs) depending on the size of the production plant. Once produced, the panels are cut to size using CNC machines. The entire wall can be prefabricated in the fabrication plant including the openings, and then be transported to the building site and quickly connected to the adjacent panels.

Another issue to address when using timber from new tree species is the need to develop some grading rules.

Due to natural differences in density and the presence of defects such as knots and grain deviation, there is a significant variation in the strength of structural timber, with some pieces eight or more times stronger than others of the same size and species. The way to overcome this drawback is to sort timber into grades based on strength. The pieces which qualify for the better grades are assigned higher working stresses and can therefore be used in smaller sections or over longer spans. The process of sorting timber on the basis of strength is known as strength grading or stress grading. Two methods of strength grading are possible: one is based on

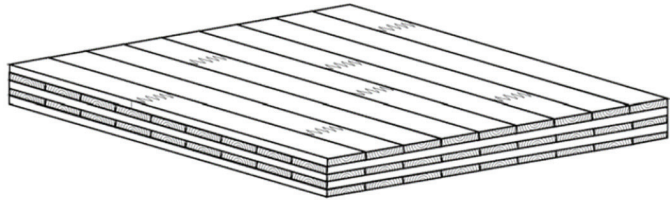

FIGURE 3. Crosslaminated timber panel (CLT)

visual inspection and the other one on the use of a grading machine.

The rules relating to the grading indicate the typical characteristics and defects in different strength classes, for a given tree species or group of species, and geographical origin. Both methods of grading, if properly taken, allow a more rational use of solid wood through a more favourable dimensioning of the structure. For the requirements of design, the classification according to strength is expressed by a series of performance profiles for the tree species and quality classes more frequently used.

All building materials have to be legally certified in order to be used as a construction element. Therefore also timber must be classified and certified. When a new wood species (not yet included in the current legislation: i.e. EN338 in EU [12]) is used as structural timber, classification rules have to be verified and possibly recalibrated. This entails a long and expensive process that includes a large number of laboratory destructive tests. The cost of these tests is an investment that has to be done at the beginning, but it will be repaid over the time from the economical, environmental and social benefits brought by development of a timber short procurement chain.

Construction materials, used in Europe, must be graded and certified by applying specific "Harmonised European Standards". For CLT, the first draft of such a standard has been released but not yet approved [13]. For that reason, the suppliers offer CLT that has been given European Technical Approval, i.e. the approval based on a testing carried out according to agreed European levels and relying on the use of certified boards. Therefore, when using a new tree species to produce CLT panels, a number of destructive tests 
will also have to be carried out on the panels to determine their mechanical properties.

As an example, since there is no grading rule for Sardinia maritime pine, within the EDENSO research projects several destructive tests are being and will be carried out on the boards and on the CLT made of maritime pine to provide, respectively, the missing grading rules and the properties of the corresponding CLT. These tests are a prerequisite to start a new timber short procurement chain using maritime pine in Sardinia.

\section{THE IDEA OF A TIMBER SHORT PROCUREMENT CHAIN}

The idea of a timber short procurement chain is based on the possibility to use locally grown timber for structural purposes, and corresponding production waste for energy production. By an appropriate forest management and planning, it is possible to grow some selected tree species such as maritime pine, eucalyptus, etc. extensively used in the Mediterranean region. The trees are harvested and the best logs are transported to local sawmills and sawn into boards. After kiln drying, the boards are either visually- or machine-graded to assign each of them to a strength class. The boards are then transported into a workshop and there used within a press to produce crosslaminated timber panels. The panels are cut to size using CNC machines and transformed into prefabricated wall and floor components. The components are then used to construct lowrise residential and office buildings. The parts of trees such as branches, bark, etc. that cannot be used for structural purposes, as well as the planks too weak and all the production waste (sawdust, etc.) are used as biomass for energy production.

The benefits of developing a timber short procurement chain are listed below.

1) By using trees for timber production it is possible to obtain a significant added value with respect to e.g. firewood. This source of revenue can then be re-invested in forest management, with all the corresponding benefits of (i) an increase in $\mathrm{CO}_{2}$ sequestration, (ii) the improvement of landscape, and (iii) the reduction of hydrogeological hazard.

2) With a better forest management and with all activities related to timber production, processing and construction, new job opportunities can be created in regions, particularly those in the countryside, often in marginal economic conditions and therefore in strong need of measures to prevent depopulation.

Some possible issues of a timber short procurement chain are listed below.

1) Accurate forest inventory and planning are needed to ensure a continuous flow of wood from the forest to the production plant. Implementation at the district level of the forest planning scheme approved by the Region [5] is vital to this aim.

2) The cost of the locally-produced CLT panels may be comparable or even higher than the material imported from abroad, due to the different scale of the production plants in countries such as Austria where the production volume is significantly higher than in less productive Mediterranean regions.

\section{THE EDENSO RESEARCH PROJECT}

As previously mentioned, the research project entitled 'Sustainable use of Sardinia forests in construction and energy production' investigates the possibility of fostering local short procurement chains in Sardinia, by exploiting locally grown maritime pine in the construction of residential buildings and for energy production. An important aim of the project is to obtain a grading rule for Sardinia maritime pine, which is a prerequisite to use this timber as a structural material. The hope is, in the future, to extend the grading rules of maritime pine also to Italy and to Europe in general, so as to foster maritime pine from all Mediterranean for structural purposes. The second aim of the research is to produce some first prototypes of CLT panels made of Sardinia maritime pine and to test the panels to destruction to investigate 
their mechanical properties. This is a potentially interesting outcome of the project as maritime pine is a tree species widely available in Italy and in the Mediterranean region and not particularly expensive. Thirdly, the project also aims to investigate the potential for using the production waste and the wood not suitable for structural purposes as energy source.

The project is funded by Sardegna Ricerche, a public research association of Sardinia, within the Cluster Research Programme "Materials for Sustainable Construction". It involves as the Department of Architecture, Design and Urban Planning of the University of Sassari; the Nuoro Forestry School of the Department of Agriculture of the University of Sassari; the Department of Civil and Environmental Engineering and Architecture of the University of Cagliari; and the IVALSA Trees and Timber Institute, a research institute of the CNR, the National Research Council of Italy, in Florence. There are also some industrial partners as part of the project. The research has been developed through the following steps.

1. With the support of the local council of Pattada, a mountain township in central Sardinia, two maritime pine plantations with stands suitable for logging and processing were identified, extensively surveyed and sampled (Figures 4, 5). On selected standing trees, based on measurements taken at different heights (Figure 6), the first preliminary grading was applied by sorting for structural and energy use.

2. Trees were harvested by a local co-operative and the logs were finally assorted based on their size and their external defects (Figure 7).

3. The logs were then transported to the local Carcangiu sawmill, where different boards required to build the grading rules and to produce the CLT panels were cut. Each board was then subjected to a non-destructive measurement of the Modulus of Elasticity using acoustic tool for measuring stress wave velocity (Viscan-Microtec).

4. After kiln drying, the required boards (approximately 950) were subjected to nondestructive measurements of their physical properties (density, humidity, defects etc.) using the machine purposely developed by Microtec. The aim was the calibration of this machine in order to enable the machine strength grading of Sardinia maritime pine.

5. The required boards were visually characterized and then tested to destruction in order to measure their strength and correlate this values to the presence of defects, knot diameters and positions, grain deviation, etc.

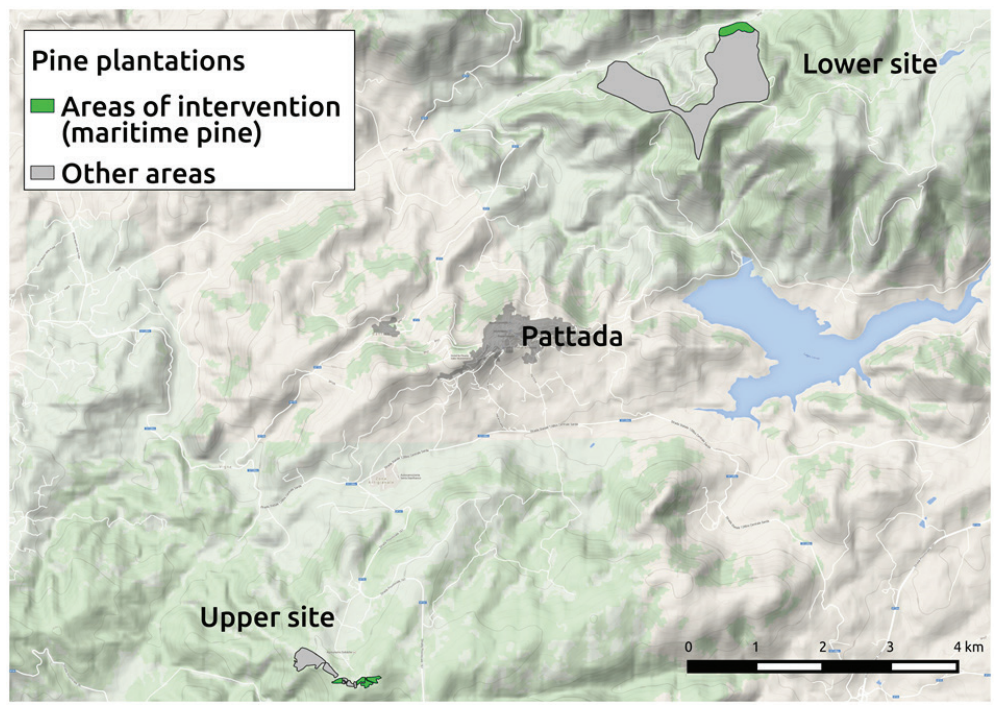

FIGURE 4. Pine stands owned by the Pattada local council 


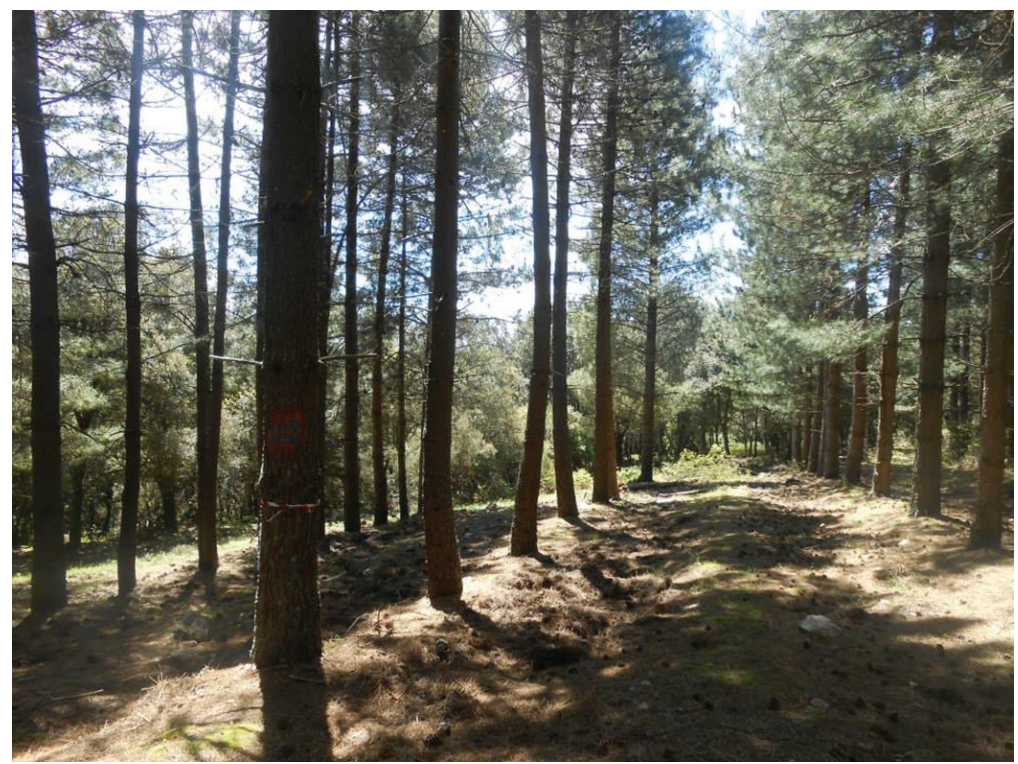

FIGURE 5. Inside the pine plantation

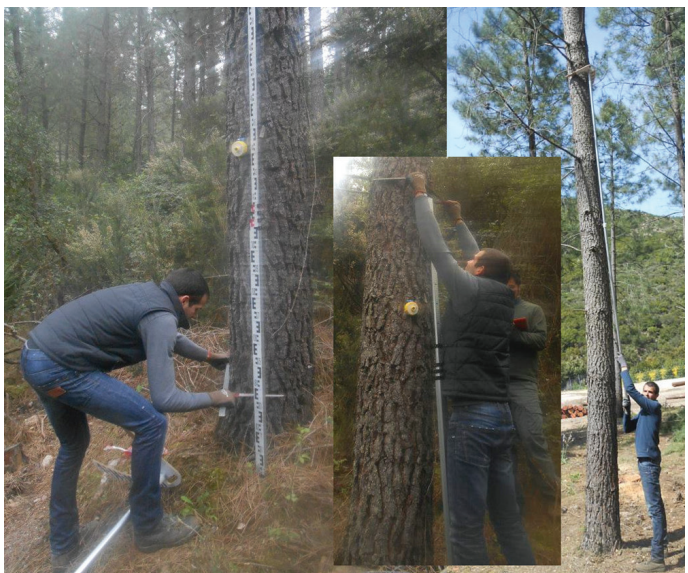

FIGURE 6. The assortment of a standing tree

6. Based on the results of phases \#4 and \#5, the visual and machine based grading rule for Sardinia maritime pine will be developed and proposed for approval.

7. By applying the newly developed grading rules, suitable boards will be selected for the production of some prototypes of CLT panels by Area Legno, a CLT producer. These panels will then be tested to destruction to determine their mechanical properties and to correlate them to the properties of the single boards.

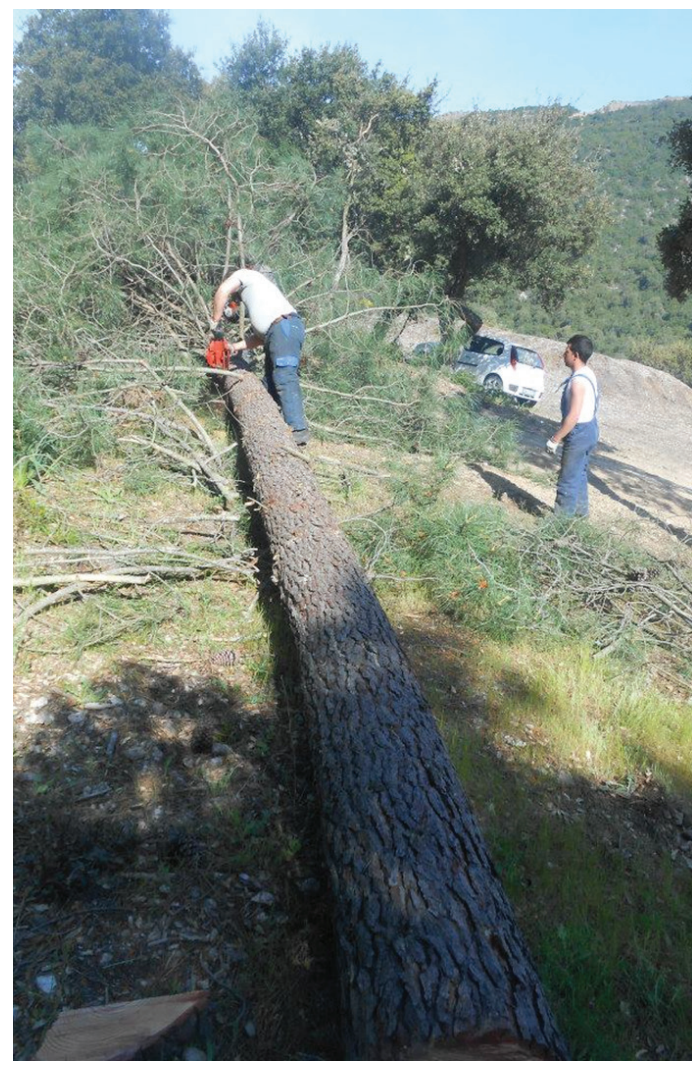

FIGURE 7. The final assortment of the bole into logs 
8. At this stage it will be possible to estimate the distribution of the wood production among the different value classes: structural timber, other boards, firewood, energy resource (chips, sawdust).

9. A small one-storey public building will finally be constructed in Sardinia out of Sardinia maritime pine by a local constructor, as a demonstration building.

\section{CONCLUSIONS}

This paper investigates the possibility to develop a timber short procurement chain. Reference is made to Sardinia, where currently no timber is produced from the local forests, but it could be easily applied to other Mediterranean regions. The idea is to start from an appropriate forest management to develop a production of timber boards that, even if low-grade, can be effectively incorporated into medium quality cross-laminated panels. These panels are prefabricated off-site into local production plants and then used as structural components in low-rise timber buildings. These buildings are easy and very quick to construct, aesthetically pleasing, seismically resistant, and sustainable. The construction waste is then used for energy production. Issues to address are (i) the need to develop appropriate grading rules for new timber species (e.g. Sardinia maritime pine), and (ii) the mechanical characterization of the crosslaminated panels made of new timber species. These issues are currently being addressed in Sardinia by a specific research project named 'EDENSO'.

The reference, in the title of the paper, to "short procurement chains" implicitly frames the work in the context of sustainability. Why is procurement chain length a relevant topic? Not only because of the environmental costs of the transportation of goods, for example, when wood pellets are imported from the other side of the Atlantic, but also because of all the ecological, social and cultural aspects that are involved. Rural areas of Sardinia are dramatically loosing inhabitants, which means that living there appears no longer sustainable. Making an income is a relevant problem but not the only one. Perceiving the choice of remaining in the home town as a meaningful perspective is equally relevant. If local timber acquires some value, the total value of the production from the forest is positively influenced. Even though the direct effect on the incomes might be quite limited, what makes the difference is the positive change in the cultural and social perspective. This change can represent a good reason for local inhabitants to decide to live at their home instead of migrating elsewhere.

The limitation of the proposed solution is that an industrial plant has to be set up and maintained to produce CLT panels, meaning that a production flow has to be maintained, year after year, above given minimum levels.

In the worst case scenario, considering all aspects, due to the limited potential production, one could conclude that such an industrial plant is not economically sustainable. In this case, having established a grading rule for the use of maritime pine grown in Sardinia as structural timber will nonetheless contribute to giving the opportunity to a more valuable production from existing plantations. When the possibility of combining this with other species might eventually appear, the option of CLT production in Sardinia might be reconsidered.

In the best case scenario, obviously, it may be concluded that the establishment and the management of the production plant is economically sustainable. In this case, by collecting and organizing in a coordinated system all the scattered productive patches of plantations (or forests) that exist throughout Sardinia, the minimum annual supply of timber required to keep the business running is estimated to be sufficient. CLT production and processing plant(s) are then established. In this scenario, great care will be required in order to limit and manage the environmental impacts that timber plantation, growing and exploitation can cause, but, on a slightly 
wider scale, this can ensure that forests will be looked after and even that living in rural or mountainous areas could develop a new appeal.

\section{Acknowledgements}

The writers gratefully acknowledge support of this research by Sardegna Ricerche, the Sardinia Research Association, through the Cluster Research Programme: 'Materials for Sustainable Construction'.

\section{REFERENCES}

1. INFC 2005 L'inventario nazionale delle foreste e dei serbatoi forestali di carbonio. INFC-2005. Secondo inventario forestale nazionale italiano. Metodi e risultati. (a cura di: Gasparini P, Tabacchi G). II Sole 24 Ore Edagricole. ISBN-10: 8850653948 (in Italian)

2. SANFILIPPO E, VANNELLI S 1993 Indagine sui risultati tecnici, economici e sociali dei rimboschimenti in Sardegna. Regione Autonoma della Sardegna, Assessorato della Difesa dell'Ambiente, Cagliari (Relazione finale convenzione registrata 20.05.1992 n.3416) (in Italian)

3. CREDITO INDUSTRIALE SARDO 1967 Atti del convegno su Prospettive economico-industriali della produzione legnosa in Sardegna. Cagliari, Italy, 24-26 February 1967. (Cagliari: Stab. tipografico P. Valdes. Sul front: sotto gli auspici della regione autonoma della Sardegna) (in Italian)

4. MAE 1981 II legno nelle attività economiche del paese: il ruolo di una materia prima rinnovabile (Congresso Nazionale). Rome, Italy, 1-4 December 1981. Ministry of Agriculture and Forestry, Rome, Italy (in Italian)

5. REGIONE AUTONOMA SARDEGNAPFAR, ASSESSORATO DELLA DIFESA DELL'AMBIENTE 2007 Piano Forestale Ambientale Regionale (Relazione generale) (in Italian). URL: http://www.regione. sardegna.it/documenti/1 $73 \quad 20080129180054$. pdf (3 November 2014)

6. CAMPUS S, D'ANGELO M, SCOTTI R 2013 Silvicultural research needs for the sustainable management in Sardinia (Italy) (in Italian). Italian Journal of Forest and Mountain Environments 68 (1): 25-41. DOI: http://dx.doi.org/10.4129/ IFM.2013.1.02

7. JOHN S, NEBEL B, PEREZ N, BUCHANAN A 2009 Environmental impacts of multi-storey buildings using different construction materials. Research Report 2008-02. University of Canterbury, Christchurch, New Zealand. URL: http://www.scnz. org/content/events/docs/MAF\%20multistorey $\% 20$ building $\% 20$ report $\% 20$ Final $\% 208$ th $\% 20$ June $\% 20$ 2009.pdf (3 November 2014)

8. GUSTAVSSON L, JOELSSON A 2010 Life cycle primary energy analysis of residential buildings. Energ Buildings 42 (2): 210-220. DOI: http:// dx.doi.org/10.1016/j.enbuild.2009.08.017

9. BUCHANAN AH, LEVINE SB 1999 Wood-based building materials and atmospheric carbon emissions. Environmental Science and Policy 2 (6): 427-437. DOI: http://dx.doi.org/10.1016/S14629011(99)00038-6

10. YATES $M$, LINEGAR $M$, DUJIC $B, 2008$ Design of an 8 storey residential tower from KLH - Cross laminated solid timber panels. In: Aratake S (ed) Proceedings of the 10th World Conference on Timber Engineering 2008, Miyazaki, Japan, 2-5 June 2008. Curran Associates, Red Hook, NY, USA, pp 2189-2196

11. NEGRI $M$, GAVRIC I, MARRA $M$, FELLIN $M$, CECCOTTI A 2012 Using low quality timber for X-LAM: Raw material characterisation and structural performance of walls under semidynamic solicitations. In: Quenneville P (ed) Proceedings of the World Conference on Timber Engineering. WCTE 2012, Auckland, New Zealand, 16-19 July 2012. Curran Associates, Red Hook, NY, USA, pp 511

12. BSI 2003 Structural timber - Strength classes. BS EN 338:2003, BSI, London, UK, 10 p

13. FprEN 16351/2013 Timber structures - Cross laminated timber - Requirements 